\title{
Mallorquines y Canarias
}

\section{David Abulafia}

Universidad de Cambridge. Conville and Caius College

http://doi.org/10.31939/bierehite/2019.06

I.

Esta ponencia discurre entre dos archipiélagos, las Islas Baleares y las Islas Canarias, que se hayan en los extremos más lejanos la España moderna pero que ya habían establecido lazos mucho antes de la conquista de las Islas Canarias, durante el breve tiempo en el que las Islas Baleares formaron parte del efímero Reino de Mallorca. Dejando de lado la incursión portuguesa de 1341 a estas islas atlánticas descrita por el gran escritor italiano Giovanni Boccaccio, las continuas expediciones mallorquinas al archipiélago canario indican el inicio de un contacto entre Canarias y Europa; aunque se puede alegar que las Islas Canarias no eran valoradas en sí mismas, sino como lugar de paso hacia territorios ricos en oro que en ese momento se asumía que quedaban por descubrir en zonas más septentrionales del continente africano. En cualquier caso, las Islas Canarias se convirtieron a finales del siglo XIV en una importante fuente de esclavos para la Península Ibérica, y también fueron objeto de actividades misionarias que resultaron en la eventual creación de una sede obispal en Telde bajo la tutela de Roma. Se puede decir mucho sobre las actividades de los misionarios en las islas canarias, pero en esta ponencia me concentraré sin embargo en las razones por las que los reyes de Mallorca se interesaron en las islas: quisiera plantear la cuestión de si sus intereses estaban dominados por intereses comerciales, por deseos de llevar a cabo una guerra santa contra el Islam, o por otros motivos. 
La historia de esta relación ha sido puesta de manifiesto desde hace varias décadas por algunos distinguidos investigadores, entre ellos el prolífico Antonio Rumeu de Armas, Elías Serra Ráfols y Francisco Sevillano Colom, quienes descubrieron en los archivos mallorquines, las referencias más antiguas de una expedición a las Canarias, que se remontan a 1342. Esta ponencia no pretende aportar datos nuevos a lo que ya se sabe sobre estas expediciones, sino contextualizar los indicios hallados por estos historiadores en un marco más amplio, es decir, el de la penetración de las naves mallorquinas más allá de el estrecho de Gibraltar y hacia el océano atlántico, el desarrollo del comercio mallorquín por lo largo y ancho de las costas atlánticas de Europa y África, los impresionantes logros de los cartógrafos mallorquines Imuchos de los cuales eran judíos), así como la importancia de la búsqueda de la ruta del oro por navegantes como Jaume Ferrer de Mallorca en 1346.

Todo esto es de gran relevancia, puesto que en el siglo XIV se establecieron nuevos lazos entre la cuenca mediterránea y la atlántica, y las expediciones a las Canarias forman parte de este proceso. Resultaría sencillo afirmar que este proceso empezó más tarde, sobre todo a partir 1415, cuando los portugueses capturaron Ceuta, pero-como veremos a continuación- las noticias sobre las islas Canarias, así como de Madeira y las Azores, preceden a las expediciones portuguesas de Henrique el Navegador, aunque Madeira y las Azores sólo fueron pobladas desde 1420 en adelante bajo cometido portugués. Además, como es bien sabido, los genoveses y portugueses fueron los verdaderos pioneros en la realización de expediciones hacia las Canarias, en primera instancia, a través de la expedición de Lançelotto Malocello a estas islas en 1336, y, posteriormente, con la expedición portuguesa de 1341 conmemorada por Giovanni Boccaccio en su fascinante tratado titulado De Canaria, para el cual no hay cabida en esta ponencia, pero que contiene una abundancia de datos sobre la vida de los isleños sin parangón en los archivos mallorquines. 


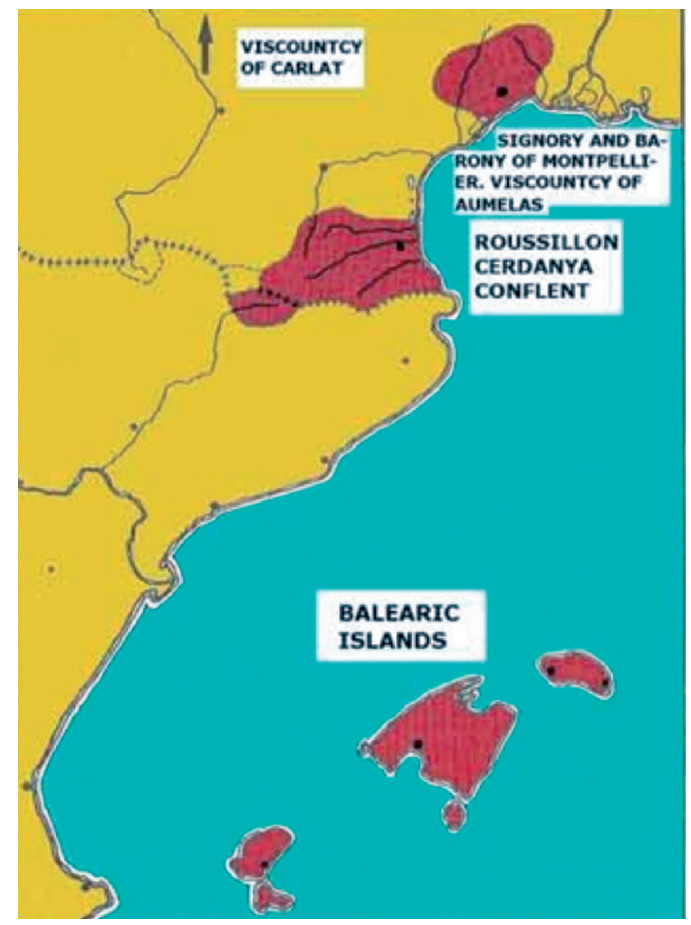

En cualquier caso, es necesario primero decir algunas palabras sobre los orígenes del Reino de Mallorca. Este reino debe su existencia a las disposiciones de la herencia por el fallecimiento, en 1276, del rey Jaime I el Conquistador, rey de Aragón y conde de Barcelona, quien había conquistado Mallorca de sus gobernantes almohades musulmanes en 1229. En su herencia, Jaime dividió los reinos de la corona aragonesa entre sus hijos Pedro III de Aragón y su hijo menor Jaime II de Mallorca, que recibió las Islas Baleares junto a los territorios que se suelen denominar la "Cataluña francesa" (el Rosellón y Cerdeña), así como el señorío de Montpelier. En tanto, Pedro retuvo Aragón, Cataluña y Valencia, un bloque de tierras más coherente pese a la amenaza constante de rebelión por parte de la población de Valencia, mayoritariamente musulmana. La excesiva dispersión de los territorios mallorquines, y su posición ceñida entre el ascendiente reino francés y los dominios aragoneses, tuvo la consecuencia de que el bisoño reino independiente, naciera en una posición de debilidad política. Pedro explotó esta debilidad, obligando a su hermano Jaime a rendirle pleitesía, en contra de las indicaciones dadas por Jaime I en su testamento. 
Así, se dio una situación inusual -aunque no única- en Europa, por la cual, un rey se convirtió en vasallo de otro (de manera similar a la relación entre Inglaterra y Escocia durante este mismo periodo). Durante la larga contienda entre los reyes de Aragón y los monarcas angevinos de Nápoles (de origen francés) por el control de Sicilia, que estalló en 1282 y se conoce como la Guerra de las Vísperas Sicilianas, el rey Jaime de Mallorca, abandonó a su hermano y se alió con Francia y Nápoles contra Aragón, dando lugar a la confiscación temporal de su reino.

Tras la restauración de Jaime al trono mallorquín en 1298, el problema de la subordinación del Reino de Mallorca a la Corona de Aragón persistió. Una fuente de tensión fue la fuerte rivalidad económica entre ambos reinos, ya que la Ciudad de Mallorca, conocida hoy en día como Palma, se convirtió en un muy próspero nexo del comercio mediterráneo, actuando como puente entre Perpiñán, Montpelier y -cuando hubo paz-Barcelona y los puertos del norte de África como Ceuta, Bugía y la ciudad de Túnez. Como Antoni Riera i Melis ha demostrado, a comienzos del siglo catorce, el derecho de los mercaderes mallorquines a operar consulados y almacenes en los puertos norteafricanos de manera independiente a sus homólogos catalanes peninsulares, generó una gran polémica. Todo esto es importante para mi argumentación, ya que el norte de África era la fuente de una valiosa mercancía, el oro, que los mallorquines más adelante persiguieron por las costas africanas más allá de las Canarias, así como de otro producto, los esclavos, que acabarían por exportar desde estas mismas islas.

Un importante acontecimiento para las comunicaciones marítimas tuvo lugar justo después de la fundación del reino mallorquín. Según parece, en 1277 los genoveses enviaron su primera expedición de larga distancia fuera del Estrecho de Gibraltar, no hacia el sur sino hacia Flandes. Desde 1281, naves mallorquinas y genovesas aparecen en los registros de Londres cargando lana. Estos son los 
inicios del comercio atlántico a través del Estrecho hacia el norte de Europa, que con el tiempo se demostró más cómodo que el largo trayecto por tierra utilizado hasta entonces. Hace algunos años encontré una abundante documentación sobre este tráfico en los Archivos Nacionales Ingleses; y más recientemente, Antonio Ortega Villaslada ha encontrado aún más documentos y ha dedicado un valioso libro a estudiar las conexiones atlánticas del reino de Mallorca entre 1230 y 1349, concentrándose en los viajes entre Flandes e Inglaterra. También se han encontrado datos de la presencia de barcos de Barcelona y Mallorca en puertos atlánticos magrebíes como Anfa (la Casablanca actual) y Safi. Una mercancía que parece haber sido muy importante para los mallorquines era el grano magrebí, ya que Mallorca no era autosuficiente en el abastecimiento de cereales a la isla, mientras que las tierras alrededor de Fez habían sido durante un tiempo, una principal fuente de esta mercancía para ciudades como Génova.

El principal problema continuó siendo que el área del Estrecho era una zona altamente peligrosa. El flujo de las aguas era a menudo agitado y la navegación hacia el Atlántico requería de un dominio de los fundamentos de la náutica y destreza naval de alto nivel. Las peligrosas condiciones de navegación sólo representan la mitad del problema. Al mismo tiempo, las potencias en ambos lados del Estrecho -los gobernantes nasrídes de Granada, los castellanos en las zonas de Andalucía recientemente conquistadas, los gobernantes mariníes en el Magreb, los señores azafíes de Ceuta- coexistían en peligrosa rivalidad. Sorprendentemente, los mallorquines intentaron mantenerse al margen de los conflictos que afloraron entre los distintos reinos, firmando acuerdos con Granada a cambio de la protección de sus mercancías. Como ya veremos, estos pactos no eran siempre posibles, y en 1338 a 1342, coincidiendo con la primera expedición mallorquina a las Islas Canarias, se desencadenó un conflicto de gran intensidad, por el control del Estrecho, entre las distintas potencias de la región. Aún así, los barcos mallorquines consiguieron llegar a Canarias. 
En ese mismo momento, el reino de Mallorca estaba atravesando una fase de creciente inestabilidad política a raíz de la degradación de las relaciones entre el rey Jaime III de Mallorca y su primo Pedro IV de Aragón. El rey de Mallorca fue acusado de haber intentado raptar al rey de Aragón durante una visita a la corte en Barcelona. El rey de Aragón a su vez trató de prohibir que el monarca mallorquín acuñara monedas para su circulación en el Rosellón. Jaime también fue acusado de haber intentado formar una alianza matrimonial con la casa inglesa de Plantagenet, cuyo dominio se extendía en ese momento hasta los Pirineos en calidad de Duques de Aquitania. Estas tensiones culminaron en 1343 con la captura de Mallorca por Pedro IV, seguido de la ocupación del Rosellón y Cerdeña un año después. Jaime quedó únicamente con los derechos sobre la ciudad de Montpelier, que finalmente vendió al rey de Francia en 1349. Aunque algunos historiadores hayan puesto en duda la estabilidad mental de Jaime III, sus tentativas para consolidar la independencia de su reino fuera del dominio aragonés no son hechos insólitos: la relación entre el reino de Mallorca y Aragón-Cataluña había sido objeto de continuas disputas desde 1276.

Todos estos datos son muy relevantes para entender las expediciones mallorquinas a las Islas Canarias. Como se verá más adelante, Jaime III intentó establecer su potestad sobre éstas, de manera que las Canarias fueran autónomas de la jurisdicción aragonesa. El dominio sobre estas islas crearía un reino marítimo compuesto en su mayoría por islas, cuyos territorios mediterráneos estuvieran equilibrados por los atlánticos. La presión por parte de los reyes aragoneses tentó a los monarcas de Mallorca a mirar hacia afuera, buscando consolidar los conocimientos adquiridos por los navegantes genoveses y portugueses que aparecen recogidos en las cartas portulanas producidas por los cartógrafos judíos de Mallorca. 


\section{II.}

Así, en resumen, Mallorca ocupaba a finales de la Edad Media una posición estratégica en el entramado mercantil formado por los comerciantes catalanes e italianos. Sin embargo, el Atlántico fue entrando también progresivamente en los planes de los hombres de negocios mallorquines y de sus colegas, de tal forma que a finales del siglo XIII se habían establecido vínculos marítimos con lugares tan lejanos como Inglaterra y Flandes. Algunas travesías desde los puertos del Atlántico iban más allá de Gibraltar y llegaban al Mediterráneo, tal como confirman las referencias a barcos del norte de la Península Ibérica, consignadas en los registros de ancoratge en el Archivo del Reino de Mallorca conservado a Palma. Efectivamente, tanto Sevilla como Mallorca se convirtieron a principios del siglo XIV en puntos de intercambio para el transporte de mercancías del Atlántico al Mediterráneo y viceversa. Se trataba, en parte, de contactos indirectos, vía Sevilla, que actuaba como une especial de terminal para los barcos genoveses, catalanes y mallorquines procedentes del Mediterráneo, y para los barcos vascos y cántabros llegados del norte de España y de puntos más lejanos. Pero la penetración del Atlántico se dirigía también hacia la zona meridional de la costa del Marruecos Atlántico. La travesía a Anfa y a otros puertos próximos debió de ser más frecuente y provechosa que los contactos marítimos con Inglaterra y Flandes, pero también es cierto que está peor documentada. La navegación hacia el sur, hasta las Canarias, era mucho más rara, aunque ha despertado el interés de una considerable literatura moderna.

Un requisito previo esencial en la creación de vinculos directos entre el Mediterráneo y el Atlántico fue de tipo tecnológico: la navegación a través del Estrecho requería gran habilidad, porque las aguas se desplazan a unos seis nudos de velocidad en el interior del Mediterráneo, que se encuentra a un nivel inferior al del Atlántico. La entrada era más fácil. Consta que en los siglos anteriores, el Rey Sigurd de Noruega y sus ancestros vikingos, habían llevado 


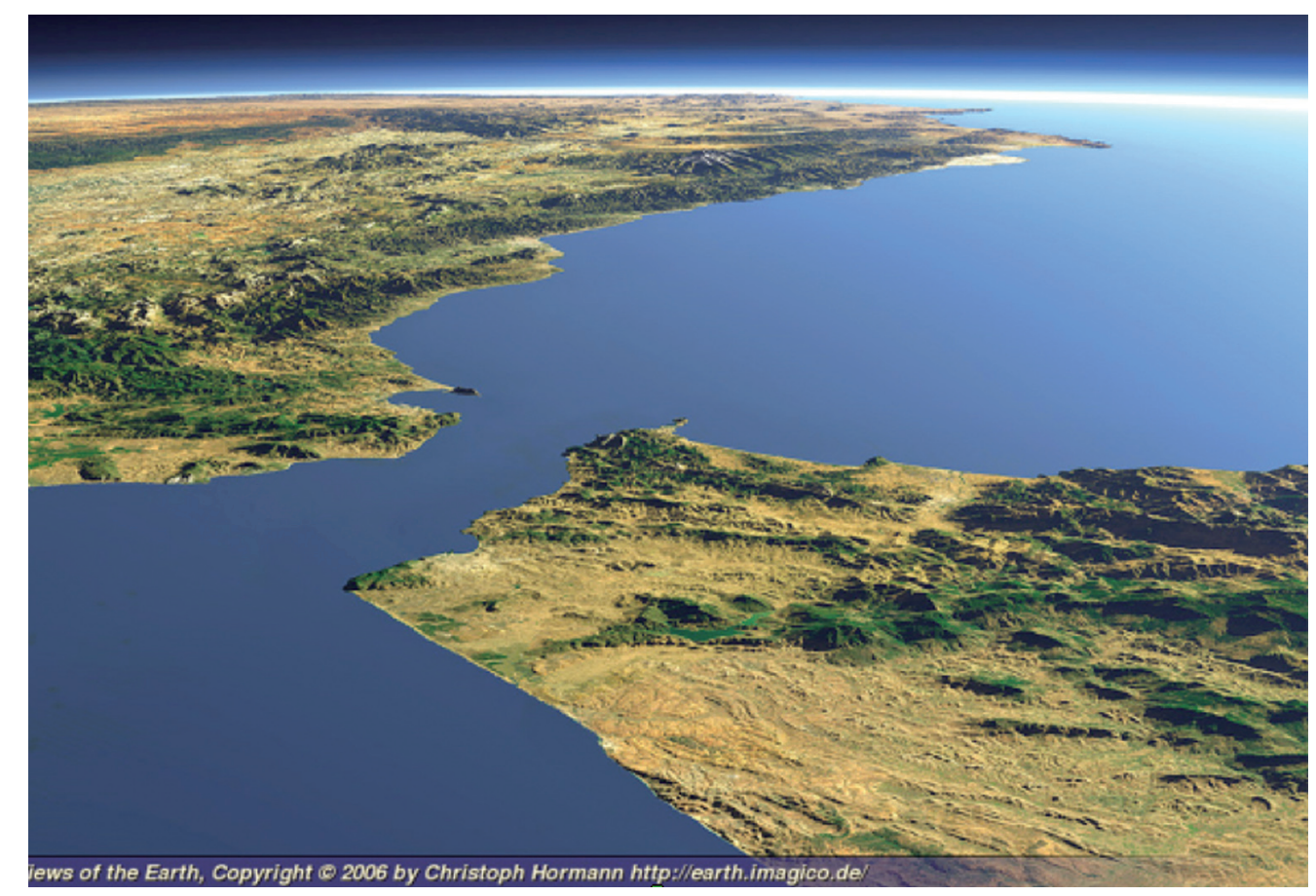

a capo ataques en las Baleares. En caso de dificultad, Ceuta podía servir como lugar de transbordo.

Otro requisito esencial en la existencia del comercio entre el Mediterráneo y el Atlántico fue que las aguas en torno a Gibraltar quedaran despejadas. Los avances cristianos en el sur de la Península lbérica y el control general del Mediterráneo conseguido por los italianos y, posteriormente, por los catalanes a lo largo de los siglos XII y XIII hizo que, hacia la década de 1270, el paso por la zona más occidental del Mediterráneo fuera mucho más seguro. Especialmente importante pudo ser la conquista de Murcia en 1265, pues reportó a los castellanos una costa mediterránea y creó un interés en la seguridad de los mares a los que tenían acceso los barcos cristianos a ambos lados de Granada.

Persistió, sin embargo, el peligro de que resurgiera un poder marítimo musulmán, como lo demuestra el hecho de que, en 1338, 
Abu'l Hasa Ali I, sultan de Marruecos, enviara dieciséis galeras a las Baleares y que en 1340, se embarcara en una invasion de la Peninsula -coaligado con el rey de Granada- lo que motivó el envío de una gran flota de dieciséis galeras y casi doscientos barcos de apoyo. La amenaza sobre Castilla y Aragón se percibía muy intensamente. Este hecho acentuó la imperiosa necesidad de mantener cuidadosamente vigilada la salida del Mediterráneo.

\section{III.}

Los mallorquines llegaron a tener un conocimiento muy preciso de las costas de la Europa atlántica y del noroeste de África, en parte gracias a que sus marineros viajaron hasta esos lugares. El análisis de la gran cantidad de mapas mallorquines que han llegado hasta nuestros días, puede llegar a revelarnos cuáles eran esos conocimientos. Una de las más notables exportaciones mallorquinas de los siglos XIV y XV fueron los mapas-portulanos y los atlas.

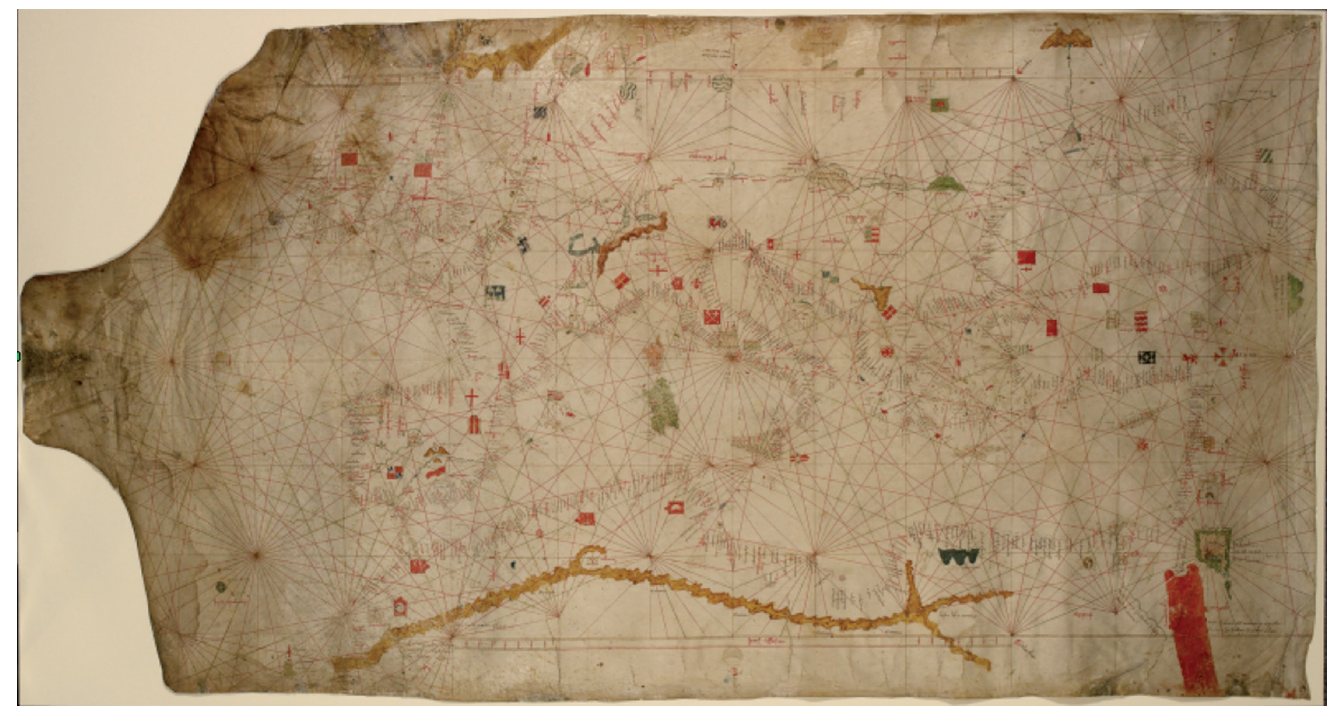

Los mapas catalanes, incluidos los de Mallorca, se pueden distinguir de los de factura italiana, porque a menudo llevan notas que, cuando tratan del África negra, son auténticas 'leyendas' en 
ambos sentidos de la palabra. Pero, además, no sólo tratan de los acontecimientos de la historia marítima catalana, sino también de los recuerdos que los catalanes tenían de dichos acontecimientos. Como veremos, la expedición de Jaume Ferrer de Mallorca a las Canarias en la década de 1340 seguía siendo, en el siglo XV, un tema recordado con orgullo. Los mapas mallorquines de finales del siglo XIV demuestran el conocimiento de la existencia del archipelago de Madeira y de las Azores, así como de las Islas Canarias, aunque en los mapas las Azores se dilatan a través del océano y son bastante más extensas. El historiador inglés Felipe Fernández-Armesto asegura que no se trata de otro caso de confabulación relacionada con el misterioso Atlántico, sino de una prueba real del conocimiento geográfico que, según él, poseían los cartógrafos en el siglo XIV, más o menos en la época de las expediciones de los mallorquines a las Islas Canarias.

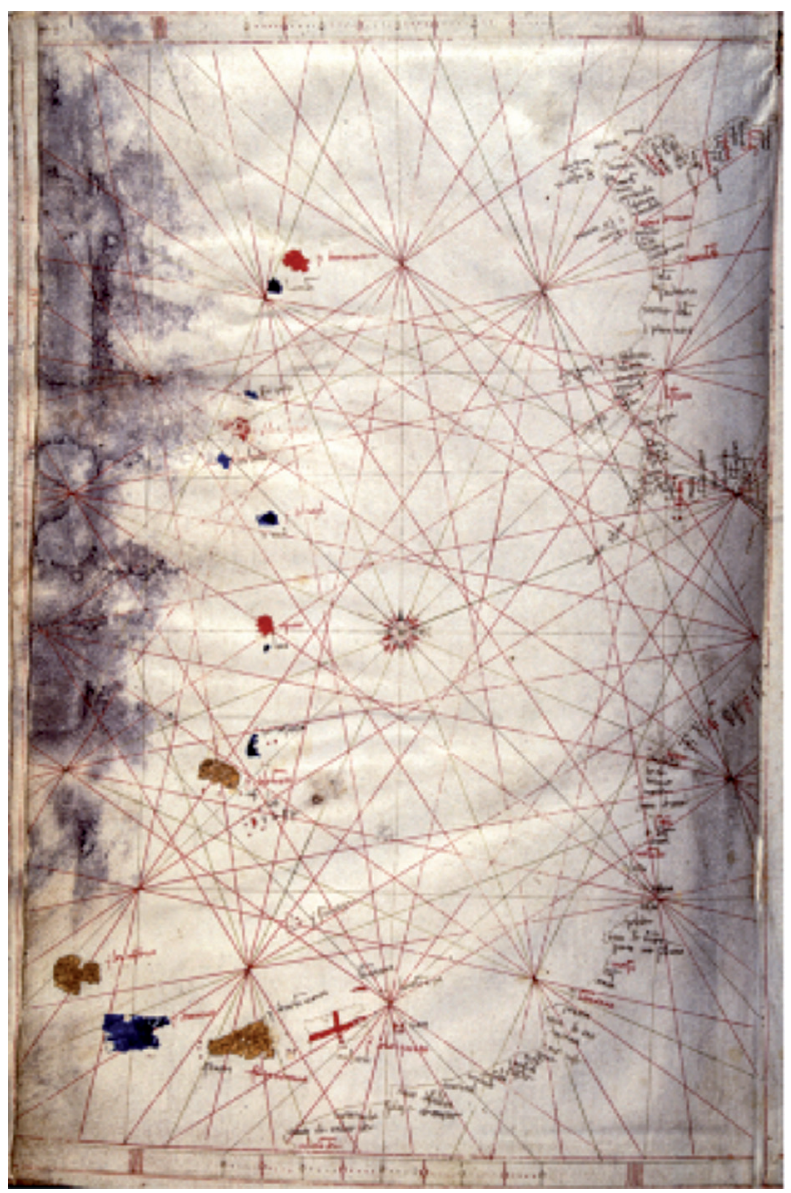


Así, las pruebas cartógraficas vienen a demostrar que los catalanes, y más concretamente los mallorquines, desarrollaron, durante los siglos XIII y XIV, impresionantes habilidades en la navegación, y fueron capaces de mantener una comunicación regular entre las Islas Baleares y las costas vecinas de Europa y África. Por ello no es sorprendente que los mallorquines comerciaran y exploraran las costas situadas más allá del Estrecho de Gibraltar.

\section{IV.}

La penetracíon de las aguas situadas al suroeste del Estrecho de Gibraltar, estaba en cierta medida determinada por los vientos y las corrientes dominantes en el Atlántico. Durante la mayor parte del año, los barcos que salían del Mediterráneo eran propensos a virar hacia las Canarias de manera natural. Parece también probado que, hacia mediados del siglo XIII, la búsqueda de oro era ya la causa principal de la penetración en el noroeste de Åfrica. La extension de la acuñación de moneda de oro en la Europa occidental, que en Florencia tuvo lugar en 1252, estimuló todavía más si cabe la ya intense búsqueda de fuentes baratas de las que obtener el preciado metal.

Por otra parte, a principios del siglo XIV, existía el convencimiento creciente de que el supremo objetivo de la Reconquista de Tierra Santa, solo podia conseguirse con la guerra naval y económica contra los musulmanes. Los escritos de Marino Sanudo insisten en la necesidad de cortar el suministro de armas occidentales al Islam, para lo que había que desviar de sus tierras el oro del Sáhara, que podia ser utilizado en parte para pagar la gran cruzada que se pretendía llevar a cabo. La famosa expedición emprendida por los hermanos genoveses Vivaldi en 1291, tenía como objetivos explícitos tanto la creación de una linea regular de suministro de especias de las Indias, como la conversion de los pueblos. Así pues, esta expedición también perseguía privar al Islam de algu- 
nas de las ventajas de ser el intermediario en el commercio entre el Lejano Oriente y la Europa occidental. La aventurada empresa de los Vivaldi tenía cierta connexion con Mallorca, ya que éstos navegaron a través de las Baleares, tal vez con la esperanza de beneficiarse de los conocimientos geográficos de los cartógrafos mallorquines.

Hacia 1300, Mallorca alcanzó mayor relieve todavía en la planificación de medidas encaminadas a frenar la fuerza del Islam gracias a los esfuerzos propagandísticos de Ramón Llull, cuya concepción de la lucha contra el Islam en el norte de África, se basaba más en el enfrentamiento de las ideas que en el de las espadas. Sin embargo, su comunidad de misioneros de Miramar disfrutó de una vida muy corta, victima quizás de los desórdenes originados por la Guerra de las Vísperas entre los reyes de Aragón y los reyes de Mallorca, Nápoles y Francia, de 1282 a 1302. En la época en que los mallorquines llegan a las Canarias, hay dos objetivos que destacan de form especial: la conversion del infiel -ya sean los musulmanes del Magreb o los indígenas paganos de las Canarias- y la penetración en la África atlántica -lo que supuestamente debía reportar ventajas en la lucha por recuperar Jerusalén. En otras palabras, en la escala de las prioridades, el simple beneficio commercial en las Canarias no debía ocupar un lugar muy elevado.

Por lo que a la presencia de mallorquines en las Canarias se refiere, los hechos están bastante claros. El 15 de abril de 1342 Guillem Pere de Mallorca, proprietario de una cocha y de un barco pequeño, obtuvo una licencia para viajar a las islas recién descubiertas en el oeste. La cocha era un tipo de barco adaptado de los utilizados en el comercio en el norte de Europa.

El 16 de abril de 1342 tres mallorquines, Francesc Desvalers, Pere Margre y Bartolomeu Giges obtuvieron licencias para viajar a las 
recién descubiertas Islas Canarias en las cochas Santa Creu y Santa Magdalena. El documento en cuestión es un mandato real promulgado por el lugarteniente del rey en Mallorca. El destino debía ser las partes insularum noviter repertarum et vulgariter nominatarum insulas Fortunarum, "la region de las islas recientemente descubiertas, en general conocidas con el nombre de islas Afortunadas", una frase un tanto paradójica que traiciona el hecho de que lo que se conocía de las islas en aquel momento, combinaba la fantasía tradicional y la información exacta.

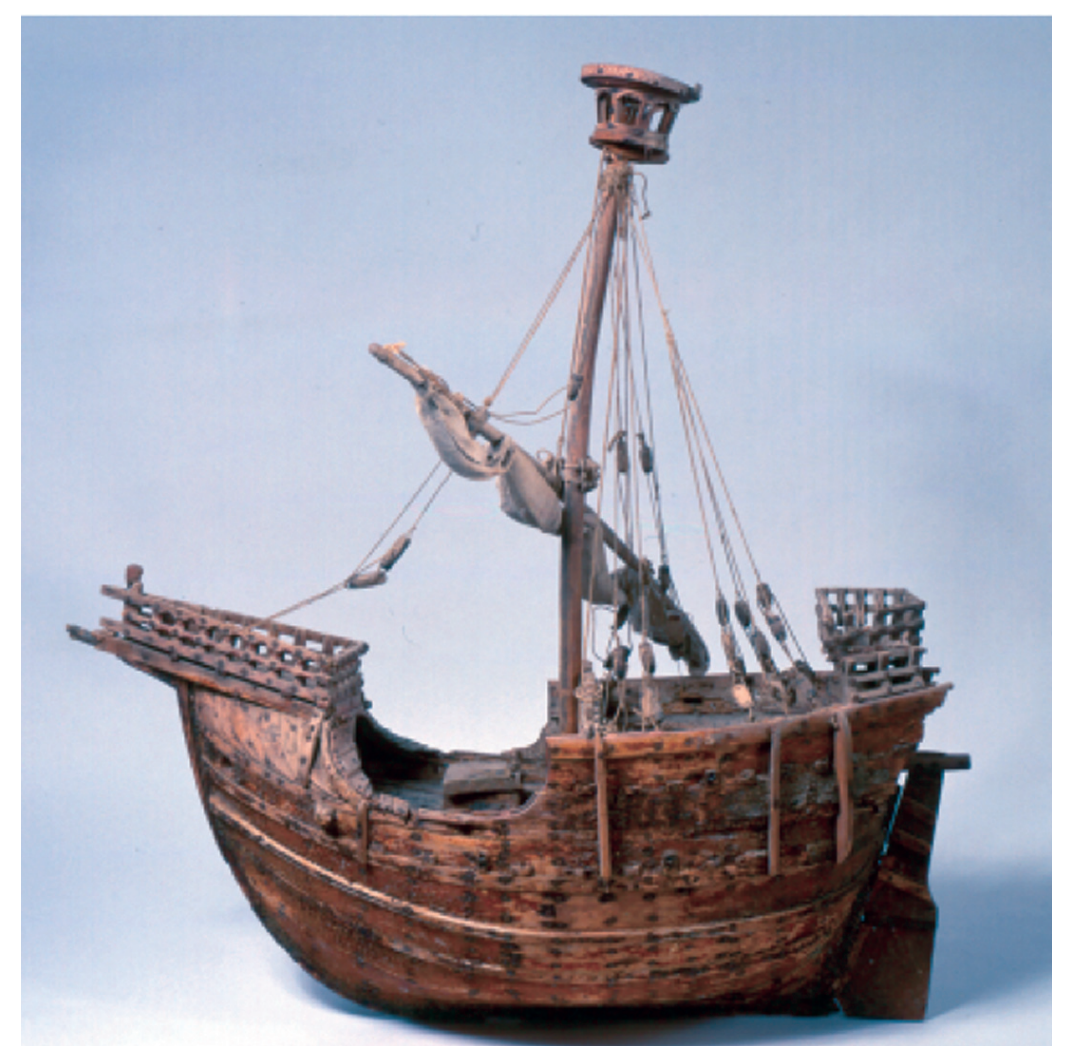

$\mathrm{Si}$, eventualmente, la expedición mallorquina tomaba alguna isla, ciudad, lugar habitado, fortaleza o castillo, la tripulación "debía reconocer como príncipe y señor a dicho rey, nuestro señor" y a ningún otro. Además, toda la jusrisdicción penal y las apelaciones debían dirigirse al rey, que sería dueño de todos los derechos de regalía en los territorios conquistados. Los conquistadores poseerían las islas como un feudo [feudum honoratum] del rey de Mallorca, que 
conservaría la jurisdicción civil y el alodio, es decir, los derechos reales de posesión de la tierra. Los ocho patroni y los armatores, los hombres mallorquines quienes pagaban el costo de la expedición, llevaron acabo un acto de homenaje al lugarteniente, en el que manifestaban su acuerdo con estas disposiciones. Así pues, el rey de Mallorca consideró la conquista de las Canarias como una oportunidad para crear un nuevo territorio allodial independiente de cualquier otra autoridad, sobre todo de la de su rival, Pedro de Aragón, aparentemente a expensas de los armatores.

Bernat Desvalls obtuvo una licencia similar en esa misma época, junto a Guilem Safont. Su barco era una cocha bayonesca, una cocha de tipo u origén vasco, llamada Santa Bàrbara.

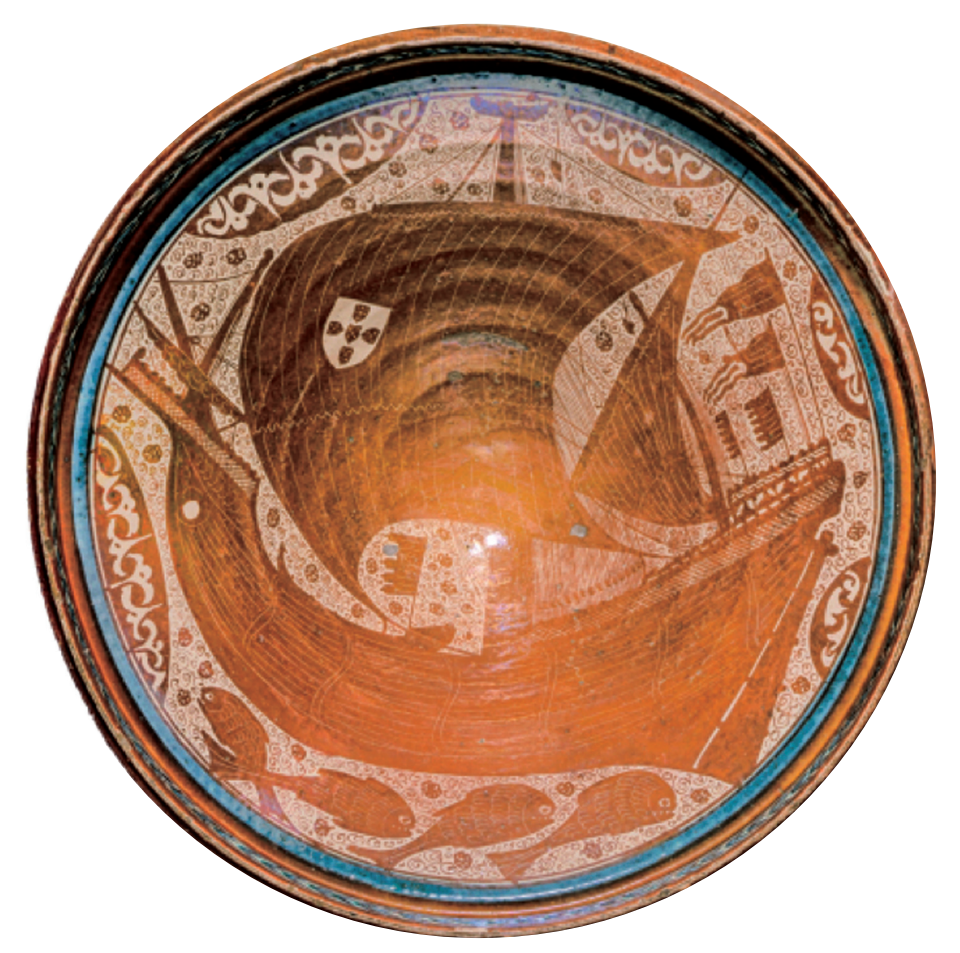

Unos días después, se concedía licencia a otra cocha bayonesca, la llamada Sant Joan, capitaneada por Domènec Gual de Mallorca. Parece que estaban organizando al menos dos expediciones a la vez y no un solo viaje. El 16 de abril de 1342, Francesc Desvalers 
fue designado capitán de dos barcos, el Sant Creu y el Santa Magdalena, al tiempo que Bernat Desvalls recibía el mismo honor con respecto al Santa Bàrbara.

No cabe duda de que la expedicíon llegó a zarapar. El 26 de octubre de 1342, Guillem Jaffe o Jofre, de Sineu, Mallorca, que anteriormente había navegado a bordo de un barco con destino a las Canarias, nombraba a un apoderado que debía presentar en su nombre, una reclamación para que le fueran pagados sus salarios, a pesar de que uno de los capitanes de los barcos, Pere Margre, ya había fallecido, supuestamente, durante la viaje. Pere Margre aparece en documentos anteriores como uno de los capitanes del Santa Creu y el Santa Magdalena. Jaffe era -según dice- un hombre joven, de menos de veinticinco años y más de veinte. La reclamación de Guillem Jaffe indica que el viaje duró cinco meses y medio. Puesto que los documentos anteriores tienen fecha de mediados de abril de 1342 y la reclamación de Jaffe data de finales de octubre, es probable que los barcos zarparan a finales de abril o principios de mayo. Llegaron a Mallorca con una mujer de nombre "Tamanizazen" que fue la prisionera de Jaffe y Margre: quondam servam oriundam de Canaria nomine Tamanizazen, "cierta sierva de origén canaria con el nombre de Tamanizazen".

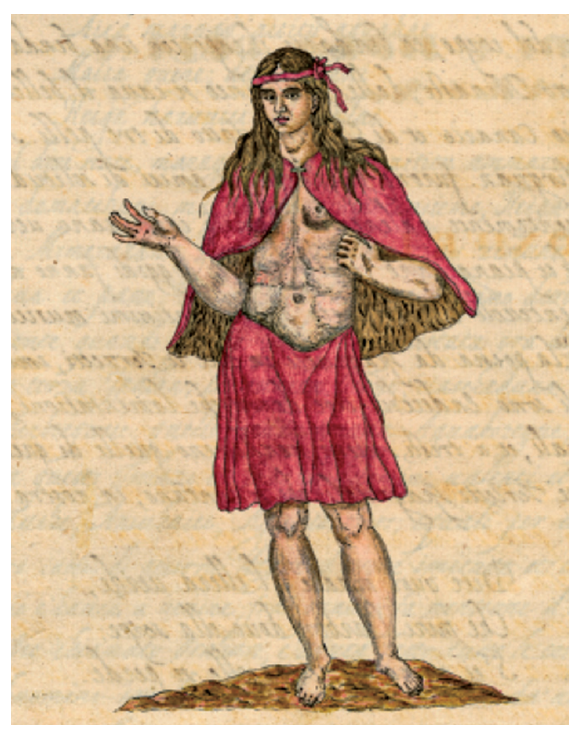


El regreso a principios de otoño tiene un certo interés. Según Fernández-Armesto, solo los vientos que soplaban en invierno permitían el paso seguro desde las Canarias hacia el norte a lo largo de la costa de África. La otra possible ruta de regreso, más adecuada para las demás épocas del año, pasaba por la isla Madeira e incluso por las Azores, en busca de los vientos del oeste. Por ello, es muy probable que la exploración de las Canarias llevara al descubrimiento de otras islas deshabitadas del Atlántico.

\section{V.}

Pero estos no eran los únicos barcos que pretendían llegar a las Canarias. El tinte púrpura conocido con el nombre de orceína que se encontraba en las islas, la piel de foca y, algo que no auguraba nada bueno, los esclavos, suscitaban un interés cada vez mayor. El 10 de Agosto de 1346, Jaume Ferrer de Mallorca ponía rumbo a las Canarias y a Rio de Oro, que supuestamente se encontraba en el África continental, a la altura del archipiélago. Este viaje fue commemorado después en las leyendas de mapas catalanes, como el atlas realizado por los Cresques de Mallorca para Carlos VI de Francia y el mappamundi del siglo XV conservado en la Biblioteca Estense de Móneda.

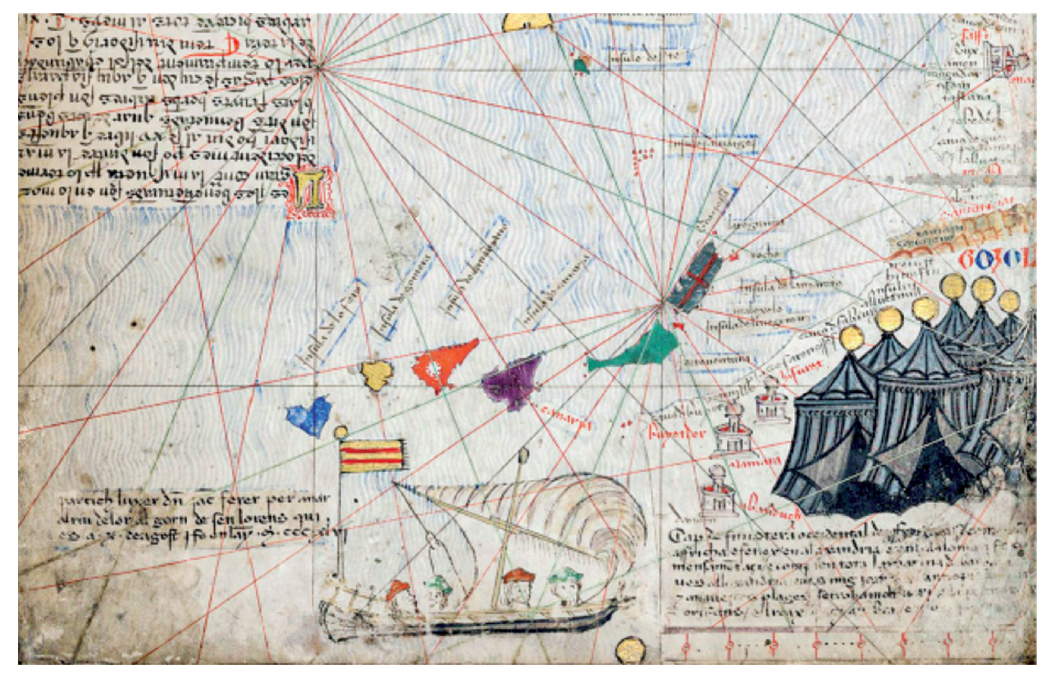


En 1351, Joan Doria, probablemente de origen genovés, Arnald Roger y Jaume Segarra, ambos residentes en Mallorca, obtenían licencias tanto del papa Clemente VI como del rey de Aragón para emprender una expedición a las Canarias. El papa Clemente VI escribió que las noticias del descubrimiento de las islas habían causado gran maravilla en la corte Pontificia; las islas eran fértiles, en ellas abundaba lo bueno y estaban muy bien pobladas, pero sus habitantes todavía no habían sido convertidos a la auténtica fe. Hasta treinta misioneros acompañaban a los barcos y, el Papa, señaló que estaba previsto, asimismo, que viajaran con ellos doce indígenas canarios que una expedición anterior había llevado a Europa y a quienes se había instruido en la lengua catalana y en le fe cristiana. Unos meses después, Clemente estableció de hecho un obispado en Telde en Gran Canaria.

En 1360, nos encontramos con una expedición conjunta de catalanes y mallorquines a bordo de dos barcos. En esta ocasión se nos informa de que los marineros fueron capturados por los indígenas en Telde, Gran Canaria, pero que fueron bien tratados y que les enseñaron el arte de construir, así como las primeras nociones de la religion cristiana. Sin embargo, finalmente fueron condenados a muerte. La presencia en este grupo de dos sacerdotes (o, según otras fuentes, cinco monjes o mendicantes) pone otra vez de manifiesto el interés de estas expediciones por la cristianización de los pueblos del África atlántica y de las Canarias. Y aún hay documentadas más expediciones hasta el año 1386, como la de los barcos de un capitán aragones, Joan Mora, que en 1366 recibió orden expresa de patrullar las Islas Canarias e impedir que las flotas de los reinos rivales establicieran bases en ellas. Parece claro que la prohibición tenía como destinatarios a Portugal, Génova o Castilla. La Guerra de Pedro de Aragón con Castilla, había creado un duro conflicto naval en el que los castellanos obtuvieron el apoyo entusiasta de sus viejos aliados e inveterados enemigos de los aragoneses: los genoveses y la Granada musulmana. En 1359, después de ser expulsado de las aguas próximas a la propia Barcelona, Pedro el 
Cruel condujo su flota a Ibiza e intentó, aunque sin éxito, conquistar las Islas Baleares. Todos los mares que se extendían desde las Baleares a las Canarias, se convertieron en potencial escenario de guerra para Castilla, Aragón y otros reinos.

El temor a posibles competidores que pudieran introducirse con más éxito en las remotas y áridas islas del Atlántico era fundado. En 1344 Papa Clemente concedía al aventurero castellano Luis de la Cerda el doble dominio de Fortunia, que comprendía las Islas Canarias y Goleta (Jalita), una isla situada en el Magreb central. Es probable que el papa, que no debía de tener una idea clara de los lugares geográficos de los que se trataba, pretendiera otorgar a don Luis, dos islas que actuaran como bases desde las que teóricamente pudiera abarcar todo el noroeste de África. Más adelante destacaremos la importancia de esa pretension. El papa recalcaba que Fortunia debía depender de su soberanía, y esa insistencia reflejaba, a un tiempo, las teorías papales sobre la autoridad global y los intentos de otros gobernantes por reclamar las islas por ellos. Como hemos visto, en 1342. Francesc Desvalers y sus colegas recibieron licencia para conquistar las Canarias, bajo la condición de que reconocieran al rey de Mallorca como su señor. La contribución, en 1351, del propio papa a una expedición mallorquina a las Canarias y su predisposición a aprobar la creación del obispado de Fortunia, ponía de manifiesto que Clemente VI era plenamente consciente de las pretensiones de los exploradores mallorquines, y deseaba tener voz y voto en el asunto. Es probable que Clemente estuviera dispuesto a prestar apoyo inmediato al ambiguo príncipe castellano Luis de la Cerda una vez que el rey de Mallorca, repentinamente derrotado por Pedro IV, había dejado de luchar por sus derechos en las Canarias.

La continua actividad de las flotas musulmanas en aguas de la Península Ibérica, era un asunto que preocupaba mucho a mallorquines y catalanes. Los aragoneses estaban mal preparados para 
contester a la amenaza de los gobernantes de Marruecos y Granada entre 1337 y 1344. Los castellanos fueron derrotados en Gibraltar en 1340; en Valencia se fraguaba un levantamiento contra sus jefes cristianos; y, de hecho, como hemos visto, el rey de Mallorca, Jaime III, ofreció ese mismo año, quince galeras (y diez en 1341) para ayudar a los catalanes a mantener a la flota mora a raya. El rey aragonés manifestaba en una carta a Jaime que la derrota castellana no había hecho más que redoblar la necesitad de destruir la amenaza musulmana. Lo que estamos intendando indicar, es que las expediciones a las Canarias, no eran algo independiente de la guerra contra Marruecos, sino que se consideraban parte de un programa a largo plazo que debía tener como resultado el estrangulamiento económico de Marruecos, al sufrir un cerco militar, poniendo fin así a la amenaza para la estabilidad del sur de la Península y para la seguridad del Mediterráneo occidental.

\section{VI.}

Las Canarias decepcionaron a aquellos colonizadores que buscaban un lugar de acceso a las rutas del oro en África occidental. Del mismo modo en que los portugueses fueron incapaces de acceder a las rutas del oro, pero posteriormente fueron recompensados con la creación y desarrollo del comercio de esclavos africanos en el siglo XV. Sus predecesores en estas aguas, los mallorquines y sus competidores, explotaron el comercio con estas islas, principalmente, como fuente de esclavos y de productos básicos como pieles y tintes. Aunque Boccaccio describió a los isleños como supervivientes de un mundo perdido viviendo en un estado de pura inocencia, la hipótesis generalizada era que vivían vidas salvajes (como también insistía Petrarca, amigo de Boccaccio). Esta teoría se usó como justificación para tratar a los isleños como gente apta para la esclavitud; si bien otros gobernantes postulaban un enfoque distinto, propuesto por el papa Clemente y por los franciscanos, que priorizaba la conversión de los isleños. La tensión generada por proponentes de ambas políticas hacia la población 
autóctona, daría lugar a uno de los mayores debates relativos a las relaciones europeas con las Canarias durante el periodo anterior a la conquista, antes de que Bethencourt, Enrique el Navegador y otros, intentaran establecer su dominio sobre las islas.

El contacto entre Mallorca y Canarias, persistió a finales del siglo XIV a través de los frailes asentados en Telde y de continuas incursiones destinadas a la obtención de esclavos. Así, hay indicios de la presencia de isleños canarios trabajando como esclavos en las Islas Baleares en distintos momentos del siglo XIV. Estas razias generaron un recelo generalizado entre los isleños hacia los frailes franciscanos que intentaban convertirles al cristianismo. Además, las incursions se incrementaron con el tiempo, aunque para 1393 muchos de los asaltantes ya eran castellanos y más tarde franceses. No hay cabida aquí para analizar el pintoresco relato de Abreu Galindo sobre la llegada de los frailes a Telde, ni del consiguiente ocaso de esta comunidad. Sin embargo, es evidente que los mallorquines jugaron un papel crucial en la apertura a Europa de estos territorios aislados, así como del mantenimiento de las rutas marítimas y el contacto continuado con las islas, hasta la llegada de unos aventureros franceses al archipiélago, para intentar establecer un señorío en Lanzarote y Fuerteventura. 